\title{
Catalytic Electrophilic Halogenation of Silyl-Protected and Terminal Alkynes: Trapping Gold(I) Acetylides vs. a Brønsted Acid-Promoted Reaction
}

\author{
Pavel Starkov, ${ }^{\text {¡† }}$ Filippo Rota, ${ }^{\mathrm{a}}$ Jarryl M. D’Oyley, ${ }^{\mathrm{a}}$ and Tom D. Sheppard ${ }^{\mathrm{a} *}$ \\ a Department of Chemistry, University College London, Christopher Ingold Laboratories, WC1H 0AJ London, UK \\ Tel: +(44)-(0)20-7679-2467; Fax: +(44)-(0)20-7679-7463; e-mail: tom.sheppard@ucl.ac.uk \\ Present Address: Department of Organic Chemistry, Weizmann Institute of Science, 76100 Rehovot, Israel
}

Received:

Supporting information for this article is available on the WWW under http://dx.doi.org/10.1002/adsc.201\#\#\#\#\#.

\begin{abstract}
In the presence of a cationic gold(I) catalyst and $N$-halosuccinimide, both trimethylsilyl-protected and terminal alkynes are converted into alkynylhalides. Further experiments showed that silyl-protected alkynes undergo electrophilic iodination and bromination under Brønsted acid catalysis, whilst terminal alkynes require a cationic gold catalyst. The former reactions probably proceed via activation of the electrophile, whilst the latter reactions proceed via a gold(I) acetylide intermediate.
\end{abstract}

Gold-catalysed halogenation was further combined with gold-catalysed hydration and subsequent annulation to provide convenient routes to iodomethylketones and fivemembered aromatic heterocycles.

Keywords: gold; alkynes; electrophilic halogenation; Brønsted acids; heterocycles; haloalkynes

\section{Introduction}

Homogeneous gold catalysis has attracted a vast amount of interest within the past decade. ${ }^{[1]}$ Most of these transformations involve the gold catalyst initially acting as a $\pi$-acid to activate carbon-carbon $\pi$-systems such as alkynes and allenes (and to a lesser degree, alkenes and dienes) towards nucleophilic attack (Scheme 1, path a). In several instances - those mostly dealing with the activation of alkenes and dienes - the role of the gold catalyst has been questioned, however. The silver salt employed for the generation of cationic gold may act as a catalyst in its own right. In addition, small quantities of strong Brønsted acid can also be generated, which can protonate unsaturated carbon-carbon bonds and promote reaction. ${ }^{[2]}$ For this reason, control experiments under acidic and/or basic conditions are desirable.

A second method of catalytic activation is possible with terminal alkynes - in situ generation of a gold(I) acetylide. This process remains relatively unexplored with only a handful of examples reported to date (Scheme 1, path b) ${ }^{[3-9]}$ These include a goldcatalysed three component coupling between alkynes, aldehydes and amines to give propargylic amines, ${ }^{[5 a]}$ a cyclisation/alkynylation cascade of 2-formyl-1ethynylarenes with terminal alkynes, ${ }^{[5 b]}$ nucleophilic

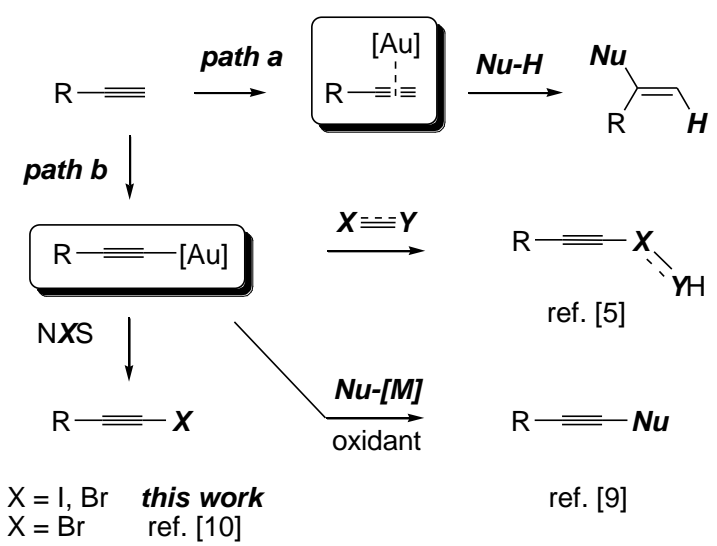

Scheme 1. Activation of alkynes by gold via formation of either a $\pi$-complex (path a) or a gold(I) acetylide (path b).

substitution at benzyl tricholoroacetamidates, ${ }^{[6]}$ and the synthesis of naphthalenes, benzofulvenes and dibenzopentalenes starting from 1,2diethynylarenes. ${ }^{[7]}$ Recently, a few reports have appeared of $\mathrm{Au}^{\mathrm{I}} / \mathrm{Au}^{\mathrm{III}}$ catalytic systems ${ }^{[8]}$ with $\mathrm{PhI}(\mathrm{OAc})_{2}$ and/or Selectfluor as terminal oxidants which achieve carbon-carbon cross-coupling via $C$ alkynylation. ${ }^{[9]}$ Although several mechanistic pathways may be operating, there is clear evidence 
that gold(III) acetylides arising from gold(I) precursors are essential for these reactions. Hence, a better understanding of the two reactivity modes of alkynes in the presence of gold catalysts, and the reactivity of the proposed $\mathrm{Au}^{\mathrm{I}}$ acetylides as nucleophiles would be desirable.

Herein, we report our observations on the cationic gold(I) and Brønsted acid catalysed electrophilic halogenation (iodination and bromination) of both terminal and trimethylsilylprotected alkynes. ${ }^{[10]} \mathrm{We}$ discuss the potential intermediacy of gold(I) acetylides and cations generated through Brønsted acid catalysis in these reactions. We also extend the halogenation reaction to yield $\alpha$-iodoketones and five-membered aromatic heterocycles directly from terminal alkynes.

\section{Results and Discussion}

\section{Gold-Catalysed Silyl Transfer}

During the course of our investigations on the Aucatalysed reaction of boronic acids with alkynes, ${ }^{[11]}$ we observed that trimethylsilyl alkynes cleanly underwent protodesilylation in the presence of catalytic quantities of $\mathrm{Ph}_{3} \mathrm{PAuNTf}_{2 .}{ }^{[12]}$ In order to investigate this Au-catalysed $\mathrm{C}-\mathrm{Si}$ bond cleavage ${ }^{[13]}$ in greater detail, we explored the reaction of three simple silylacetylenes in the presence of 2iodophenol as a silyl trap (Scheme 2a).

Interestingly, complete silyl transfer to the phenol was observed in under three hours in the case of trimethylsilylacetylene, whereas transfer of a triethylsilyl group was considerably slower $(66 \%$ conversion in $16 \mathrm{~h}$ ) and triisopropylsilylacetylene was completely inert under these reaction conditions. In a similar manner, and only in the presence of methanol, trimethylsilyl-protected alkyne 1a was deprotected and then gradually converted to 2bromoacetophenone (Scheme 2b). Whilst these transformations may find use in selective protection of phenols and direct deprotection/hydration of silylprotected alkynes under exceptionally mild conditions, we wished to gain an insight into the role of the gold catalyst and the potential generation of a gold(I) acetylide intermediate in these reactions.

A plausible mechanism is depicted in Scheme 3. Coordination of $\mathrm{Au}$ to the alkyne generates cation $\mathbf{3}$, perhaps best represented by resonance form 3', where the $\mathrm{Au}-\mathrm{C}$ bond and/or the $\mathrm{Si}-\mathrm{C}$ bond stabilise(s) the carbocation. The alcohol nucleophile then attacks the silicon atom resulting in alkynylgold(I) species $\mathbf{4}$ and the protonated silyl ether 5. Cation $\mathbf{5}$ can in turn protonate the gold acetylide to give the terminal alkyne 2 and regenerate the $\mathrm{Au}(\mathrm{I})$ cation.

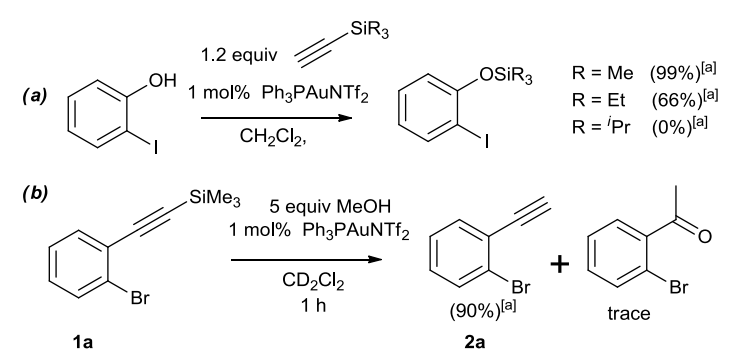

Scheme 2. Gold-catalysed silyl transfer from alkynes to (a) 2-iodophenol and (b) methanol. ${ }^{[\mathrm{a}]}$ Conversions given in parentheses. ${ }^{[14]}$

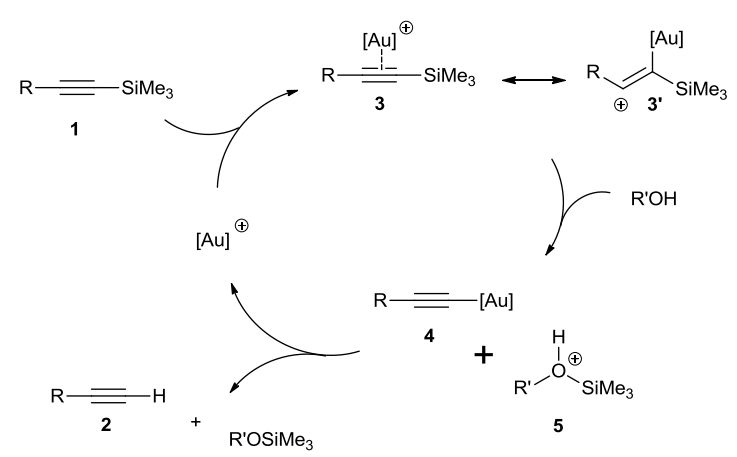

Scheme 3. Plausible mechanism for the gold-catalysed silyl transfer reaction.

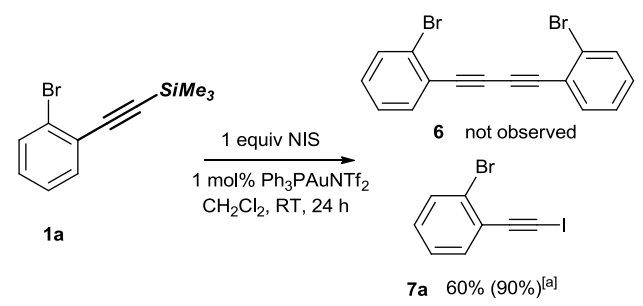

Scheme 4. Gold-catalysed iodination of a trimethylsilyl alkyne. ${ }^{[\mathrm{a}]}$ Conversion given in parentheses. ${ }^{[14]}$

\section{Halogenation of Trimethylsilyl-Protected Alkynes}

In an attempt to trap the gold(I) acetylide intermediate $\mathbf{4}$, trimethylsilylalkyne $\mathbf{1 a}$ was treated with $\mathrm{Au}$ catalyst in the presence of $\mathrm{N}$ iodosuccinimide (Scheme 4). Pleasingly, the corresponding iodoalkyne $\mathbf{7 a}$ was generated with no sign of the homocoupled product 6 .

In order to determine whether the iodination might be catalysed by traces of acid present in the Au-catalyst ${ }^{[3]}$ we examined the reaction of alkyne 1a with NIS in the presence of a catalytic quantity of $\mathrm{TfOH}$ (Table 1). Interestingly, with $2 \mathrm{~mol} \% \mathrm{TfOH}$, iodoalkyne 7a was formed in good yield after stirring for $24 \mathrm{~h}$ at ambient temperature (entry 1). Triflimide $\left(\mathrm{Tf}_{2} \mathrm{NH}\right)$ was also able to catalyse the halogenation, giving an excellent yield of the iodoalkyne after only $1 \mathrm{~h}$. 
The $\mathrm{Tf}_{2} \mathrm{NH}$-catalysed halogenation conditions were applied to the synthesis of a selection of haloalkynes (Table 1). ${ }^{[15,16]}$ The formation of arylalkynyl halides (entries 1-4) was considerably more efficient than the halogenation of an alkynylsilane bearing an aliphatic group (entry 5). Bromination (entry 6) was slightly less efficient than iodination (entry 1). Notably, alkynes bearing both electron-donating (entry 2) and electron-withdrawing (entries 3 and 4) aryl substituents could be halogenated effectively. This acid-catalysed halogenation reaction offers an extremely convenient route to haloalkynes directly from trimethylsilylalkynes, which are available commercially or can be conveniently prepared by Sonogashira coupling of arylhalides. This provides a useful alternative to the existing silver-catalysed methods for halodesilylation of silylalkynes. ${ }^{[16 i, 16 j]}$

Table 1. Acid-catalysed halogenation of TMS-protected alkynes.

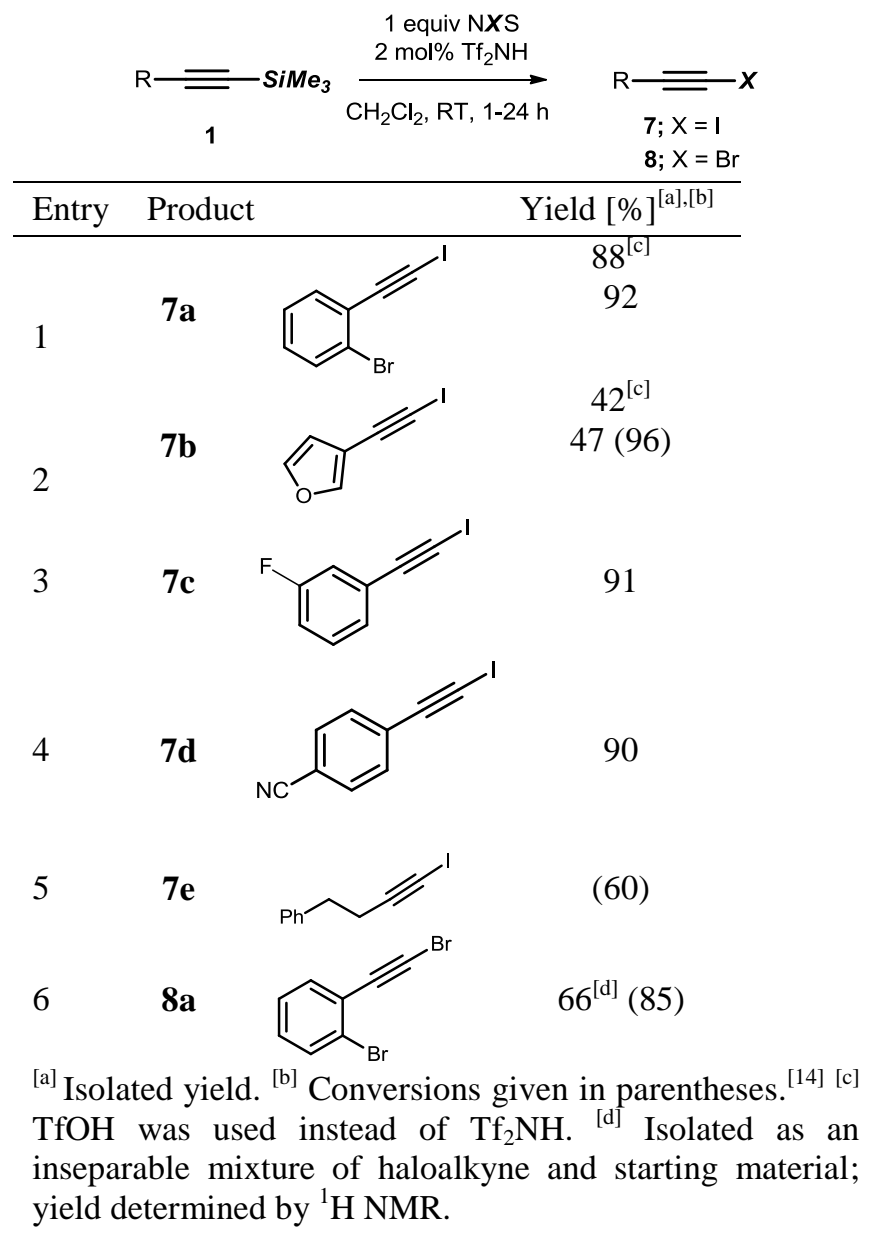

\section{Halogenation of Terminal Alkynes}

The formation of gold acetylides directly from terminal alkynes and cationic Au catalyst was recently proposed as a key step in a number of $\mathrm{Au}$ mediated transformations. ${ }^{[4-9]}$ We therefore decided to explore whether such an acetylide could be trapped with $\mathrm{N}$-iodosuccinimide to give the corresponding iodoalkyne directly from a terminal alkyne. Pleasingly, iodination of terminal alkynes was found to occur in the presence of only $1 \mathrm{~mol} \% \mathrm{Ph}_{3} \mathrm{PAuNTf}_{2}$ at room temperature in $\mathrm{CH}_{2} \mathrm{Cl}_{2}$ (Table 2). We investigated the application of this reaction to a range of simple alkynes $\mathbf{2}$ (Table 2).

Table 2. Gold-catalysed halogenation of terminal alkynes.

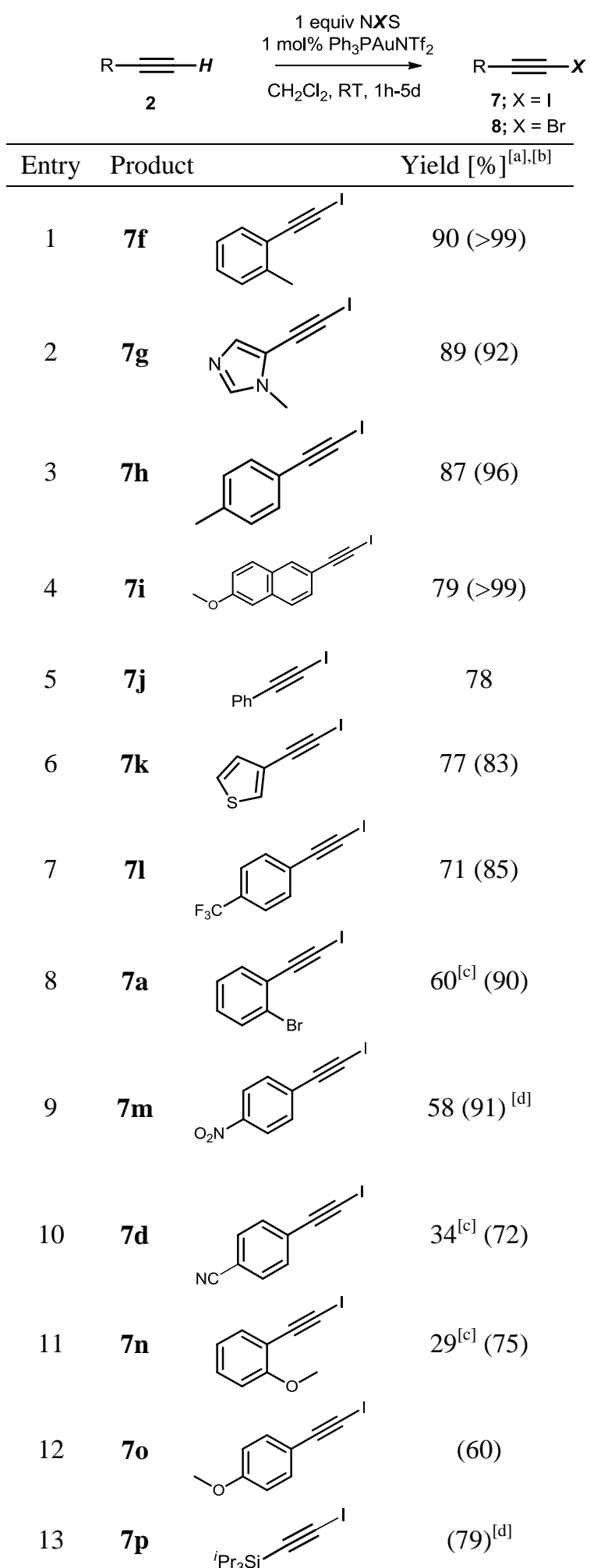




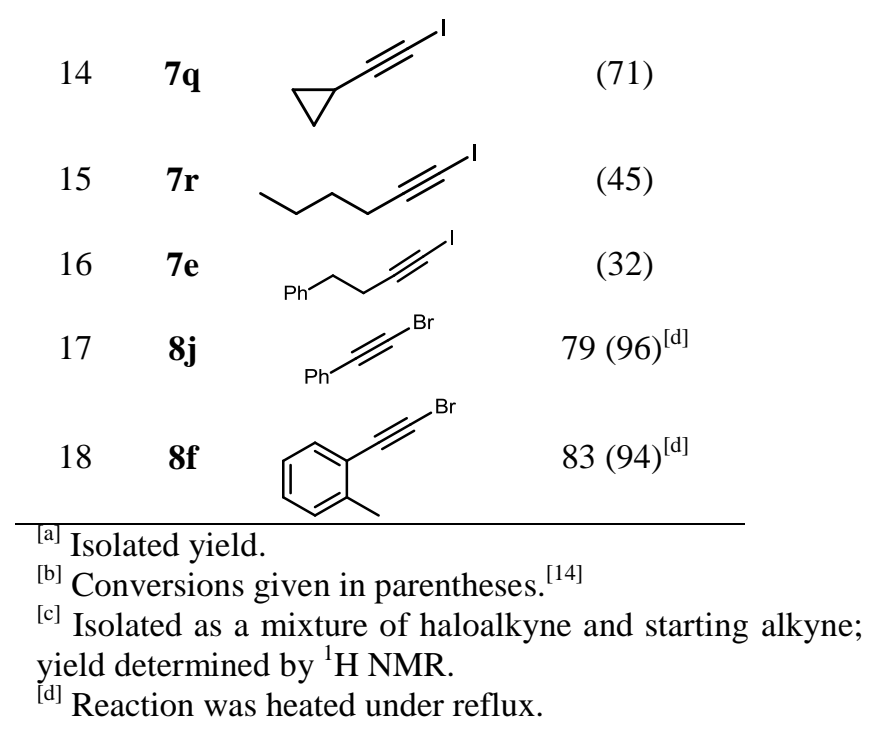

Simple arylalkynes were iodinated in moderate to excellent yield, including both electron-rich (Table 2, entries 1, 3-5 and 11-12), electron-deficient (entries 7, 9,10 ) and heterocyclic (entries 2 and 6) examples. In all cases, good to excellent conversion to the iodoalkyne was observed and the low isolated yields obtained in some cases are due to the difficulties encountered in the purification of the product. Several aliphatic alkynes, including TIPS-acetylene, could also be iodinated though the resulting iodoalkynes (entries 13-16) could not be readily purified. The reactions were very clean, however, with the crude reaction mixture generally containing only starting materials, succinimide and the iodoalkyne product. Iodination of 20 proceeded with moderate conversion but the iodoalkyne 7o (Table 2, entry 16) could not be separated from starting material and an unidentified byproduct. However, it was possible to use the crude iodoalkyne in subsequent transformations without difficulty (vide infra, Scheme 7).

As with the trimethylsilylalkynes, bromination was found to be less efficient (Table 2; entries 17 and 18) but good yields of alkynylbromides were obtained when the reaction was heated under reflux in $\mathrm{CH}_{2} \mathrm{Cl}_{2}$. In comparison, bromination of $\mathbf{2 f}$ in 1,4dioxane was recently reported to require as much as $10 \mathrm{~mol} \%{ }^{t} \mathrm{Bu}_{3} \mathrm{PAuNTf}_{2}$ to give $\mathbf{8 f}$ in $52 \%$ isolated yield, ${ }^{[10]}$ while $\mathrm{Ph}_{3} \mathrm{PAuNTf}_{2}$ was reported by the same authors to be ineffective. In our hands, however, 1 mol\% $\mathrm{Ph}_{3} \mathrm{PAuNTf}_{2}$ proved to be sufficient to effectively promote both iodinations and brominations in chlorinated solvents (polar aprotic solvents such as acetonitrile were found to be unsuitable for the reaction). Alkynes containing basic nitrogen functionality and methyl propiolate did not readily undergo halogenation (Figure 1).

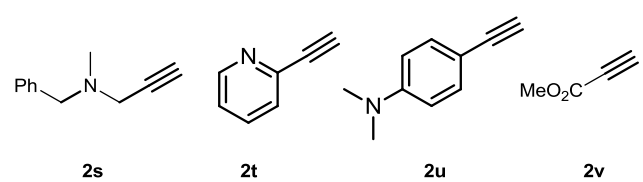

Figure 1. Terminal alkynes that did not undergo goldcatalysed iodination.

\section{Mechanism of the Halogenation Reactions}

In control experiments, the reaction of 4tolylacetylene $\mathbf{2 h}$ with NIS in the absence of $\mathrm{Au}$ catalyst, or in the presence of $\mathrm{Tf}_{2} \mathrm{NH}$ alone, did not lead to the formation of iodoalkyne $\mathbf{7 h}$. This suggests that: $(i)$ cationic $\mathrm{Au}$ is necessary for the halogenation of terminal alkynes; (ii) the silyl group is essential for the Brønsted acid-mediated reaction. The gold(I) and acid catalysed halodesilylations showed a similar chemoselectivity in competition experiments (Table 3). When a 1:1 mixture of trimethylsilyl alkynes 1a and 1d was treated with a substoichiometric quantity of NIS in the presence of either $\mathrm{Ph}_{3} \mathrm{PAuNTf}_{2}$ (entry 1) or $\mathrm{Tf}_{2} \mathrm{NH}$ (entry 2), the more electron-rich alkyne 1a was iodinated selectively in both cases. The goldcatalysed reaction was slower with only $44 \%$ conversion after 1 hour whereas the acid-catalysed reaction had already reached completion.

Table 3. Halogenation of a mixture of electronically different TMS-protected or terminal alkynes.

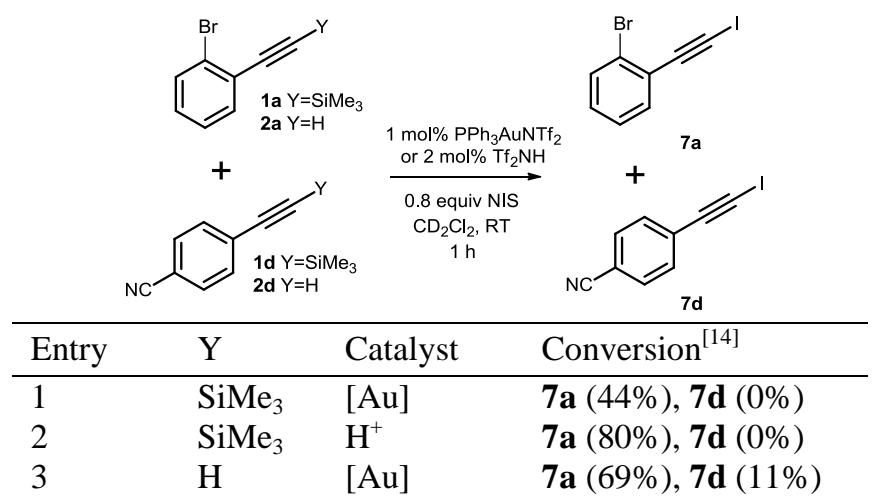

These observations support the fact that both catalysts mediate the halogenation via similar reaction mechanisms with the Au catalyst either acting as a Lewis acid or as a source of protic acid. ${ }^{[2 f, 17]}$ The Aucatalysed-halogenation of a mixture of the two terminal alkynes $\mathbf{2 a}$ and $\mathbf{2 d}$ reached completion within an hour, and also led to preferential iodination of the more electron-rich alkyne but the selectivity was lower (entry 3 ). This suggests that this reaction proceeds via a different mechanism from the Au/acidcatalysed halogenation of TMS-protected alkynes. 


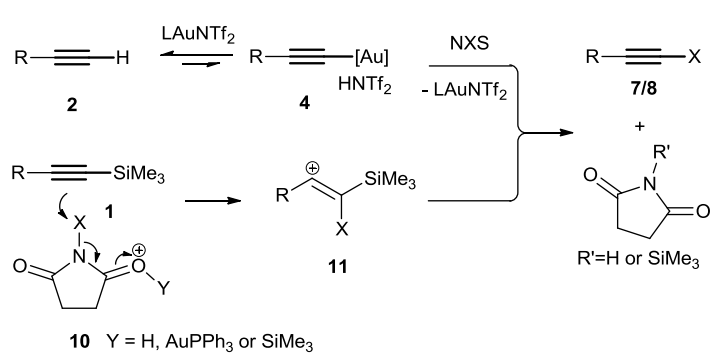

Scheme 5. Plausible mechanisms for the gold and acid-catalysed electrophilic halogenations.

Plausible mechanisms for the acid and gold catalysed halogenation reactions are shown in Scheme 5. In the presence of the gold catalyst, small quantities of gold acetylide $\mathbf{4}$ can be formed from the terminal alkyne 2. ${ }^{[10]}$ After trapping this acetylide with NXS to give haloalkyne $7(\mathrm{X}=\mathrm{I})$ or $\mathbf{8}(\mathrm{X}=\mathrm{Br})$ and succinimide, the gold catalyst is regenerated. Notably, this is achieved with a commercially available catalyst $\left(\mathrm{Ph}_{3} \mathrm{PAuNTf}_{2}\right)$ under simple homogeneous reaction conditions without the intermediacy of a silver salt. ${ }^{[2 \mathrm{~g}, 1 \mathrm{~d}]}$ The higher reactivity of more electron-rich alkynes is perhaps due to a stronger interaction with the cationic gold catalyst which may facilitate generation of the gold acetylide.

The halogenation of trimethylsilyl alkynes in the presence of either gold or $\mathrm{Tf}_{2} \mathrm{NH}$ catalyst probably proceeds via activation of the electrophile (10). ${ }^{[18]}$ This activated electrophile is then able to react with the silylalkyne to give silicon-stabilised carbocation 11, which subsequently undergoes silyl transfer to succinimide to generate the haloalkyne 7/8.

In order to determine whether the gold catalyst is involved in the halogenation of trimethylsilylalkynes or simply acts as a source of Brønsted acid, we studied the iodination of $\mathbf{1 a}$ in the presence of the hindered base, 2,6-di-tert-butylpyridine. Neither the gold nor Brønsted acid catalysed halogenation reactions proceeded under these conditions and the silylalkyne remained unchanged. In order to confirm that the base did not inhibit the gold catalyst, we also carried out the halogenation of terminal alkyne $2 \mathbf{f}$ in the presence of 2,6-di-tert-butylpyridine. Although the reaction was slower than usual, a $25 \%$ conversion to the haloalkyne was observed after $1 \mathrm{~h}$. These observations confirm that the halogenation of trimethylsilylalkynes proceeds under Brønsted acid catalysis (Scheme 5, Y=H), with the gold catalyst simply acting as a source of a small quantity of acid (presumably $\mathrm{Tf}_{2} \mathrm{NH}$ ). This mechanism would account for the much higher reactivity of electron-rich alkynes due to the increased stability of carbocation 11.

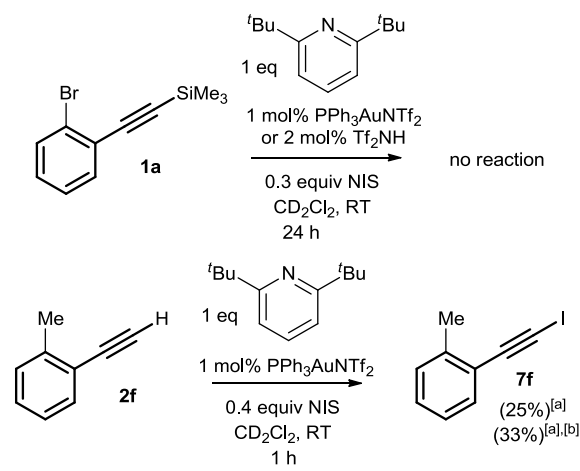

Scheme 6. Halogenation reactions in the presence of a base. ${ }^{[\mathrm{a}]}$ Conversions given in parentheses. ${ }^{[14]}{ }^{[\mathrm{b}]}$ Reaction without 2,6-di-tert-butylpyridine.

\section{Direct Synthesis of $\alpha$-Iodoketones and Aromatic Heterocycles from Terminal Alkynes}

Since the halogenation reactions were generally very clean, we envisaged the use of in situ generated haloalkynes in subsequent transformations. Hence, iodination of $\mathbf{2} \mathbf{j}$ and $\mathbf{2 0}$ was combined with $\mathrm{Au}-$ catalysed alkyne hydration ${ }^{[19]}$ to give

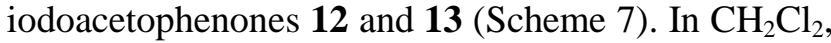
a mixture of iodoketone $\mathbf{1 2}$ and its dimethyl acetal was formed. ${ }^{[20]}$ Switching the solvent to chloroform, however, gave the iodoketone $\mathbf{1 2}$ directly in good yield. Pleasingly, this overall transformation was also achieved with 4-ethynylanisole $\mathbf{2 0}$, despite the fact that we had previously been unable to isolate the corresponding iodoalkyne 7o from the halogenation reaction (vide supra, Table 2).

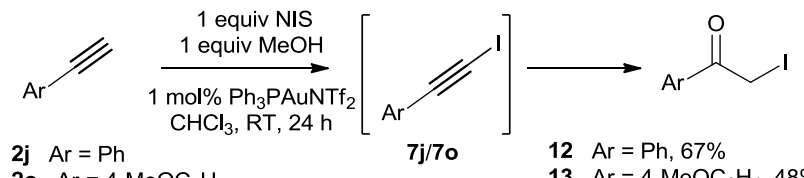

2o $\mathrm{Ar}=4-\mathrm{MeOC}_{6} \mathrm{H}_{4}$

$13 \mathrm{Ar}=4-\mathrm{MeOC}_{6} \mathrm{H}_{4}, 48 \%$

Scheme 7. Direct conversion of terminal alkynes into iodomethylketones.

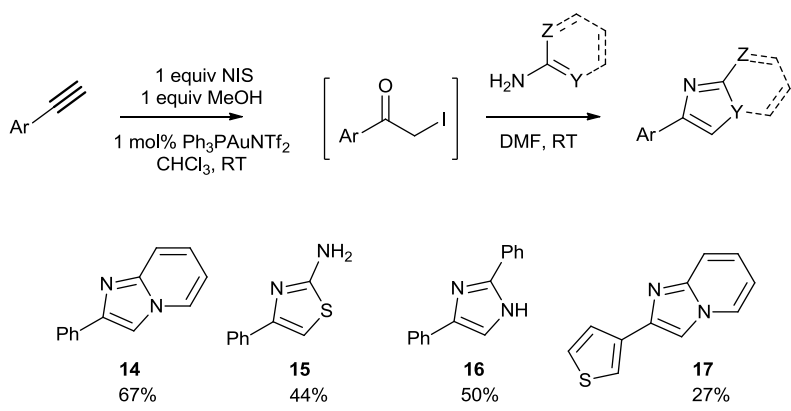

Scheme 8. Concise synthesis of five-membered aromatic heterocycles from terminal alkynes.

This reaction sequence was then extended by a subsequent condensation of the $\alpha$-iodoketone ${ }^{[21]}$ to form either a thiazole (15), an imidazole (16) or an 
azaindolizine $(\mathbf{1 4}, \mathbf{1 7})$ directly from a terminal alkyne with no requirement to purify any of the intermediate compounds (Scheme 8). Overall, in a single operation, these sequences provide an expedient access to functionalised five-membered aromatic heterocycles from simple terminal alkynes, demonstrating the synthetic utility of these gold-catalysed tandem processes.

\section{Conclusion}

In summary, we have shown that trimethylsilylprotected acetylenes are halodesilylated by treatment with $N$-halosuccinimide in the presence of a low catalytic loading of Brønsted acid. Furthermore, terminal alkynes are efficiently converted into either iodoalkynes or bromoalkynes in an Au-catalysed process in moderate to excellent yield. This latter reaction is not catalysed by Brønsted acid and probably proceeds via trapping of an in situ generated gold(I) acetylide. We have also demonstrated goldcatalysed tandem iodination/hydration of terminal alkynes, which can be further extended via annulation, to provide an effective route to a variety of fivemembered aromatic heterocycles.

\section{Experimental Section}

Full experimental details are provided in the supporting information.

\section{Brønsted Acid-Catalysed Halogenation of Trimethylsilyl Alkynes}

Brønsted acid (TfOH or $\mathrm{Tf}_{2} \mathrm{NH}, 2 \mathrm{~mol} \%$ ) was added to a solution of alkyne or trimethylsilyl alkyne (1 equiv) and NXS (1 equiv) in $\mathrm{CH}_{2} \mathrm{Cl}_{2}(0.1 \mathrm{M})$. The reaction mixture was stirred at room temperature and monitored by NMR or TLC. Upon completion, the solvent was evaporated and the crude material was purified by filtration through a silica pad eluting with PE/EtOAc.

\section{Gold-Catalysed Halogenation of Terminal Alkynes}

$\left[\mathrm{Ph}_{3} \mathrm{PAuNTf}\right]_{2} \cdot \mathrm{PhMe}(0.5 \mathrm{~mol} \%)$ was added to a solution of terminal alkyne (1 equiv) and NXS (1 equiv) in $\mathrm{CH}_{2} \mathrm{Cl}_{2}(0.1 \mathrm{M})$ and the mixture was left to stir at RT. Upon completion, the mixture was concentrated and purified by filtration through a silica pad eluting with PE/EtOAc.

\section{Acknowledgements}

This work was supported by the Engineering and Physical Sciences Research Council (EP/E052789/1), the Leverhulme Trust (F/O0 134/CL) and the UCL PhD program in Drug Discovery.

\section{References}

[1] For recent reviews, see: a) S. P. Nolan, Acc. Chem. Res. 2011, 44, 91-100; b) A. Corma, A. Leyva-Pérez, M. J. Sabater, Chem. Rev. 2011, 111, 1657-1712; c) A. Pradal, P. Y. Toullec, V. Michelet, Synthesis 2011, 10, 1501-1514; d) J. Xiao, X. Li, Angew. Chem. 2011, 123, 7364-7375; Angew. Chem. Int. Ed. 2011, 50, 7226-7236; e) N. D. Shapiro, F. D. Toste, Synlett 2010, 675-691; f) A. S. K. Hashmi, Angew. Chem. 2010, 122, 5360-5369; Angew. Chem. Int. Ed. 2010, 49, 5232-5241; g) E. Jiménez-Núñez, A. M. Echavarren, Chem. Rev. 2008, 108, 3326-3350; h) J. Muzart, Tetrahedron 2008, 64, 5815-5849; i) D. J. Gorin, B. D. Sherry, F. D. Toste, Chem. Rev. 2008, 108, 3351-3378. j) Z. Li, C. Brouwer, C. He, Chem. Rev. 2008, 108, 3239-3265; k) A. Arcadi, Chem. Rev. 2008, 108, 3266-3325; 1) A. S. K. Hashmi, Chem. Rev. 2007, 107, 3180-3211; m) A. S. K. Hashmi, G. J. Hutchings, Angew. Chem. 2006, 118, 8064-8105; Angew. Chem. Int. Ed. 2006, 45, 7896-7936; n) A. Fürstner, P. W. Davies, Angew. Chem. 2007, 119, 3478-3519; Angew. Chem. Int. Ed. 2007, 46, 3410 3449; o) D. J. Gorin, F. D. Toste, Nature 2007, 446, 395-403.

[2] a) W.-J. Shi, Y. Liu, P. Butti, A. Togni. Adv. Synth. Catal. 2007, 349, 1619-1623; b) J. G. Taylor, L. A. Adrio, K. K. Hii, Dalton Trans. 2010, 39, 1171-1175; c) T. C. Wabnitz, J.-Q. Yu, J. B. Spencer, Chem. Eur. J. 2004, 10, 484-493; d) T. Schwier, A. W. Sromek, D. M. L. Yap, D. Chernyak, V. Gevorgyan, J. Am. Chem. Soc. 2007, 129, 9868-9878; e) N. D. Shapiro, V. Rauniyar, G. L. Hamilton, J. Wu, F. D. Toste, Nature 2011, 470, 245-249. f) T. T. Dang, F. Boeck, L. Hintermann, J. Org. Chem. 2011, 76, 9353-9361; For silver salt effects in gold catalysis, see: g) D. Wang, R. Cai, S. Sharma, J. Jirak, S. K. Thummanapelli, N. G. Akhmedov, H. Zhang, X. Liu, J. L. Petersen, X. Shi, J. Am. Chem. Soc. 2012, 134, 9012-9019.

[3] a) J. Carlos Lima, L. Rodríguez, Chem. Soc. Rev. 2011, 40, 5442-5456; b) A. Simonneau, F. Jaroschik, D. Lesage, M. Karanik, R. Guillot, M. Malacria, J.-C. Tabet, J.-P. Goddard, L. Fensterbank, V. Gandon, Y. Gimbert, Chem. Sci. 2011, 2, 2417-2422; c) H. Lang, S. Ko, S. Back, G. Rheinwald, G. V. Koten, Synthesis 2001, 1968-1972;

[4] a) G. C. Fortman, A. Poater, J. W. Levell, S. Gaillard, A. M. Z. Slawin, I. D. W. Samuel, S. P. Nolan, Dalton Trans. 2010, 39, 10382-10390; b) T. J. Brown and R. A. Widenhoefer, Organometallics 2011, 30, 6003 6009 ; c) S. Sun, J. Kroll, Y. Luo, L. Zhang, Synlett 2011, 23, 54-56; d) A. Leyva-Pérez, A. Doménech, S. I. Al-Resayes, A. Corma, ACS Catal. 2012, 2, 121126.

[5] a) C. Wei, C.-J. Li, J. Am. Chem. Soc. 2003, 125, 9584-9585; b) X. Yao, C.-J. Li, Org. Lett. 2006, 8, 
1953-1955; c) V. Lavallo, G. D. Frey, S. Kousar, B. Donnadieu, G. Bertrand, Proc. Natl. Acad. Sci. 2007, 104, 13569-13573.

[6] C. Li, F. Mo, W. Li, J. Wang, Tetrahedron Lett. 2009, 65, 6053-6056.

[7] a) A. S. K. Hashmi , I. Braun , P. Nösel , J. Schädlich , M. Wieteck , M. Rudolph , F. Rominger, Angew. Chem. 2012, 124, 4532-4536; Angew. Chem. Int. Ed. 2012, 51, 4456-4460; b) A. S. K. Hashmi, M. Wieteck, I. Braun, P. Nösel, L. Jongbloed, M. Rudolph, F. Rominger, Adv. Synth. Catal. 2012, 354, 555-562.; c) A. S. K. Hashmi, I. Braun, M. Rudolph, F. Rominger, Organometallics 2012, 31, 644-661.

[8] For recent reviews, see: a) M. N. Hopkinson, A. D. Gee, V. Gouverneur, Chem. Eur. J. 2011, 17, 82488262 ; b) C. Nevado, T. de Haro, in: New Strategies in Chemical Synthesis and Catalysis, (Ed.: B. Pignataro), Wiley-VCH Verlag GmbH \& Co. KGaA, Weinheim, 2012; c) C. Nevado, T. de Haro, Synthesis 2011, 16, 2530-2539.

[9] a) T. de Haro, C. Nevado, J. Am. Chem. Soc. 2010, 132, 1512-1513; b) M. Hopkinson, J. Ross, G. Giuffredi, A. D. Gee, V. Gouverneur, Org. Lett. 2010, 12, 4904-4907; For an interesting example of Aucatalysed $\mathrm{C}-\mathrm{C}$ bond formation that may also involve Au-acetylides, see: c) J. P. Brand, C. Chevalley, R. Scopelliti, J. Waser, Chem. Eur. J. 2012, 18, 56555666.

[10] For a recent report on gold-catalysed conversion of terminal alkynes to bromoalkynes, see: A. LeyvaPérez, P. Rubio-Marqués, S. S. Al-Deyab, S. I. AlResayes, ACS Catal. 2011, 1, 601-606.

[11]a) C. Körner, P. Starkov, T. D. Sheppard, J. Am. Chem. Soc. 2010, 132, 5968-5969; b) M. N. Pennell, M. G. Unthank, P. Turner, T. D. Sheppard, J. Org. Chem. 2011, 76, 1479-1482; c) T. D. Sheppard, Synlett 2011, 1340-1344; d) M. N. Pennell, P. G. Turner, T. D. Sheppard, Chem. Eur. J. 2012, 18, 4748-4758.

[12] N. Mézailles, L. Ricard, F. Gagosz, Org. Lett. 2005, 7, 4133-4136.

[13] For previous examples of Au-catalysed desilylation of alkynes, see: a) A. S. K. Hashmi, E. Enns, T. M. Frost, S. Schäfer, W. Frey, F. Rominger, Synthesis 2008, 2707-2718; b) V. Mamane, P. Hannen, A. Fürstner, Chem. Eur. J. 2004, 10, 4556-4575; c) I. V. Seregin, V. Gevorgyan, J. Am. Chem. Soc. 2006, 128, 12050-12051.

[14] All conversions were measured by ${ }^{1} \mathrm{H}$ NMR without internal standard, and are calculated as the $\%$ of the desired product present, of the total amount of starting material and product(s). Except where noted in the text, all reactions proceeded cleanly and the NMR spectrum contained only the expected starting materials/products.

[15] For recent examples of applications of haloalkynes, see: a) A. S. Dudnik, V. Gevorgyan, Angew. Chem. 2010, 122, 2140-2142; Angew. Chem. Int. Ed. 2010, 49, 2096-2098; b) J.-S. Tang, M. Tian, W.-B. Sheng, C.-C. Guo, Synthesis 2012, 541-546; c) G. Cahiez, O. Gager, J. Buendia, Angew. Chem. 2010, 122, 1300-1303; Angew. Chem. Int. Ed. 2010, 49, 1278-1281; d) J. E. Hein, J. C. Tripp, L. B. Krasnova,
K. B. Sharpless, V. V. Fokin, Angew. Chem. 2009, 121, 8162-8165; Angew. Chem. Int. Ed. 2009, 48, 8018-8021; e) S. Nicolai, J. Waser, Org. Lett. 2011, 13, 6324-6327; f) K. A DeKorver, M. C. Walton, T. D. North, R. P. Hsung, Org. Lett. 2011, 13, 4862-4865; g) D. L. Usanov, H. Yamamoto, J. Am. Chem. Soc. 2011, 133, 1286-1289; h) C. A. Campos, J. B. Gianino, D. M. Pinkerton, B. L. Ashfeld, Org. Lett. 2011, 13, 5680-5683; i) H. Yoshida, Y. Asatsu, Y. Mimura, Y. Ito, J. Ohshita, K. Takaki, Angew. Chem. 2011, 123, 9850-9853; Angew. Chem. Int. Ed. 2011, 50, 96769679; j) Y. Wen, A. Wang, H. Jiang, S. Zhu, L. Huang, Tetrahedron Lett. 2011, 52, 5736-5739; k) Y. Ano, M. Tobisu, N. Chatani, J. Am. Chem. Soc. 2011, 133, 12984-12986; 1) H. Liu, C. Chen, L. Wang, X. Tong, Org. Lett. 2011, 13, 5072-5075; m) Y. Ano, M. Tobisu, N. Chatani, Org. Lett. 2012, 14, 354-357; n) T. Kawano, N. Matsuyama, K. Hirano, T. Satoh, M. Miura, J. Org. Chem. 2010, 75, 1764-1766; o) M. S. Reddy, Y. K. Kumar, N. Thirupathi, Org. Lett. 2012, 14, 824-827; p) B. C. Chary, S. Kim, D. Shin, P. H. Lee, Chem. Commun. 2011, 47, 7851-7853; q) S. Wang, P. Li, L. Yu, L. Wang, Org. Lett. 2011, 13, 5968-5971; r) M. Yamagishi, K. Nishigai, T. Hata, H. Urabe, Org. Lett. 2011, 13, 4873-4875; s) S. Xu, C.-T. Lee, H. Rao, E.-ichi Negishi, Adv. Synth. Catal. 2011, 353, 2981-2987.

[16] For examples of synthesis of haloalkynes, see: a) T. Jeffrey, J. Chem. Soc., Chem. Commun. 1988, 909910; b) A. Casarini, P. Dembech, A. Ricci, G. Seconi, Tetrahedron Lett. 1991, 32, 2169-2170; c) J. Yan, J. Li, D. Cheng, Synlett 2007, 2442-2444; d)G. Eglington, W. Mccrae, J. Chem. Soc. 1963, 22952299; e) H. Hofmeister, K. Annen, H. Laurent, R. Wiechert, Angew. Chem. 1984, 96, 720-722; Angew. Chem. Int. Ed. 1984, 23, 727-729; f) U. HalbesLetinois, J.-M. Weibel, P. Pale, Chem. Soc. Rev. 2007, 36, 759-769; g) Y. Yamamoto, Chem. Rev. 2008, 108, 3199-3222; h) Y. Hori, Y. Nagano, H. Uchiyama, Y. Yamada, H. Taniguchi, Chem. Lett. 1978, 73-76; i) T. Nishikawa, S. Shibuya, S. Hosokawa, M. Isobe, Synlett 1994, 485; j) T. Lee, H. R. Kang, S. Kim, S. Kim, Tetrahedron 2006, 62, 4081-4085.

[17] A. S. K. Hashmi, Catal. Today 2007, 122, 211-214.

[18] a) G. A. Olah, Q. Wang, G. Sandford, G. K. Surya Prakash, J. Org. Chem. 1993, 58, 3194-3195; b) G. K. S. Prakash, T. Mathew, D. Hoole, P. M. Esteves, Q. Wang, G. Rasul, G. A. Olah, J. Am. Chem. Soc. 2004, 126, 15770-15776.

[19] For selected examples of Au-catalysed hydrations, see: a) P. Nun, R. S. Ramón, S. Gaillard, S. P. Nolan, J. Organomet. Chem. 2011, 696, 7-11; b) L. Hintermann, A. Labonne, Synthesis 2007, 11211150; c) A. Corma, V. R. Ruiz, A. Leyva-Pérez, M. J. Sabater, Adv. Synth. Catal. 2010, 352, 1701-1710; d) J. Roithová, Š. Janková, L. Jašíková, J. Váňa, S. Hybelbauerová, Angew. Chem. 2012, 124, 85038507; Angew. Chem., Int. Ed. 2012, 51, 8378-8382.

[20] S. D. Higgins, C. B. Thomas, J. Chem. Soc., Perkin Trans. I 1982, 235-242.

[21] a) T. J. Donohoe, M. A. Kabeshov, A. H. Rathi, I. E. D. Smith, Org. Biomol. Chem. 2012, 2, 1093-1101; 
b) T. J. Donohoe, M. A. Kabeshov, A. H. Rathi, I. E.

D. Smith, Synlett 2010, 2956-2958; c) H. Tomoda, T.
Hirabno, S. Saito, T. Mutai, K. Araki. Bull. Chem. Soc. Jpn. 1999, 72, 1327-1334. 


\section{FULL PAPER}

Catalytic Electrophilic Halogenation of Silyl-

Protected and Terminal Alkynes: Generation of

Gold(I) Acetylides vs. a Brønsted Acid-Promoted

Reaction

Adv. Synth. Catal. 2012, 354, Page - Page

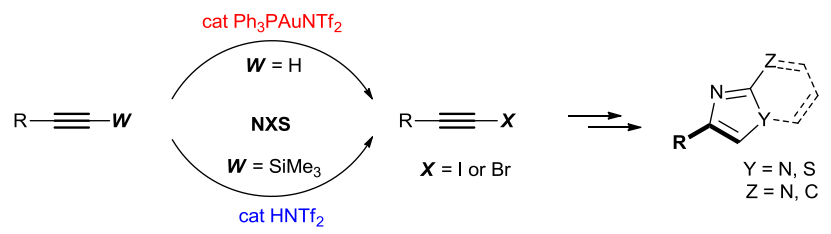

Pavel Starkov, Filippo Rota, Jarryl M. D’Oyley and

Tom D. Sheppard* 